\title{
Overexpression of Dyrk1A, a Down Syndrome Candidate, Decreases Excitability and Impairs Gamma Oscillations in the Prefrontal Cortex
}

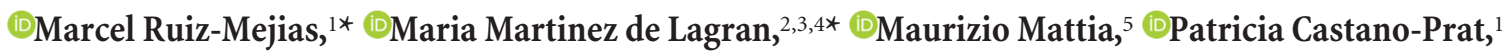 \\ CLorena Perez-Mendez, ${ }^{1}$ Laura Ciria-Suarez, ${ }^{1}$ OThomas Gener, ${ }^{2,3,4}$ Belen Sancristobal, ${ }^{2,3,4}$ @ Jordi García-0jalvo, ${ }^{3}$

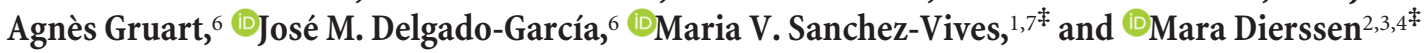 \\ ${ }^{1}$ Systems Neuroscience, August Pi i Sunyer Biomedical research Institute (IDIBAPS), 08036 Barcelona, Spain, ${ }^{2}$ Centre for Genomic Regulation (CRG), \\ Barcelona Institute of Science and Technology, 08003 Barcelona, Spain, ${ }^{3}$ Pompeu Fabra University (UPF), 08003 Barcelona, Spain, ${ }^{4}$ Centre for Biomedical \\ Research on Rare Diseases (CIBERER) 08003 Barcelona, Spain, ${ }^{5}$ National Institute of Health, 00161 Rome, Italy, ${ }^{6}$ Neuroscience Department, Pablo de \\ Olavide University 41013 Seville, Spain, and ${ }^{7}$ Catalan Institution for Research and Advanced Studies (ICREA) 08010 Barcelona, Spain
}

The dual-specificity tyrosine phosphorylation-regulated kinase DYRK1A is a serine/threonine kinase involved in neuronal differentiation and synaptic plasticity and a major candidate of Down syndrome brain alterations and cognitive deficits. DYRK1A is strongly expressed in the cerebral cortex, and its overexpression leads to defective cortical pyramidal cell morphology, synaptic plasticity deficits, and altered excitation/inhibition balance. These previous observations, however, do not allow predicting how the behavior of the prefrontal cortex (PFC) network and the resulting properties of its emergent activity are affected. Here, we integrate functional, anatomical, and computational data describing the prefrontal network alterations in transgenic mice overexpressing Dyrk1A (TgDyrk1A). Using in vivo extracellular recordings, we show decreased firing rate and gamma frequency power in the prefrontal network of anesthetized and awake TgDyrk1A mice. Immunohistochemical analysis identified a selective reduction of vesicular GABA transporter punctae on parvalbumin positive neurons, without changes in the number of cortical GABAergic neurons in the PFC of TgDyrk1A mice, which suggests that selective disinhibition of parvalbumin interneurons would result in an overinhibited functional network. Using a conductance-based computational model, we quantitatively demonstrate that this alteration could explain the observed functional deficits including decreased gamma power and firing rate. Our results suggest that dysfunction of cortical fast-spiking interneurons might be central to the pathophysiology of Down syndrome.

Key words: Down syndrome; DYRK1A; gamma oscillations; prefrontal cortex; transgenic mouse model

\section{Significance Statement}

DYRK1A is a major candidate gene in Down syndrome. Its overexpression results into altered cognitive abilities, explained by defective cortical microarchitecture and excitation/inhibition imbalance. An open question is how these deficits impact the functionality of the prefrontal cortex network. Combining functional, anatomical, and computational approaches, we identified decreased neuronal firing rate and deficits in gamma frequency in the prefrontal cortices of transgenic mice overexpressing Dyrk1A. We also identified a reduction of vesicular GABA transporter punctae specifically on parvalbumin positive interneurons. Using a conductance-based computational model, we demonstrate that this decreased inhibition on interneurons recapitulates the observed functional deficits, including decreased gamma power and firing rate. Our results suggest that dysfunction of cortical fast-spiking interneurons might be central to the pathophysiology of Down syndrome.

\section{Introduction}

The dual-specificity tyrosine-(Y)-phosphorylation-regulated kinase $1 \mathrm{~A}(D Y R K 1 A)$ gene is located on chromosome $21 \mathrm{q} 22.13$

Received June 28, 2015; revised Jan. 12, 2016; accepted Jan. 14, 2016.

Author contributions: M.R.-M., M.M.d.L., J.G.-O., M.V.S.-V., and M.D. designed research; M.R.-M., M.M.d.L., P.C.-P., T.G., B.S., A.G., and J.M.D.-G. performed research; M.M., L.P.-M., L.C.-S., and B.S. analyzed data; M.R.-M., M.M.d.L., M.V.S.-V., and M.D. wrote the paper. within the Down syndrome critical region. It encodes a serine/ threonine kinase highly expressed in the brain and plays key roles in cell proliferation and survival, neuronal differentiation, synaptic plasticity, and neurodegeneration (for review, see Park et 
al., 2009; Tejedor and Hammerle, 2011; Dierssen, 2012). Altered expression levels of DYRK1A produce cognitive impairment and neuronal alterations linked to intellectual disability (Dierssen, 2012). DYRK1A haploinsufficiency in partial monosomy of chromosome 21 in humans (HSA21) leads to microcephaly and intellectual disability (Møller et al., 2008; van Bon et al., 2011; Courcet et al., 2012; Ji et al., 2015). Altered learning and memory and neuronal microarchitecture are also present in heterozygous Dyrk1A mice (Fotaki et al., 2002; Benavides-Piccione et al., 2005). Overexpression of Dyrk1A in mice leads to important behavioral and cognitive impairments and neuronal alterations that recapitulate those detected in trisomy 21 (Altafaj et al., 2001; Martinez de Lagran et al., 2004, 2012; Dierssen, 2012; Thomazeau et al., 2014), suggesting that overabundance of this kinase is sufficient to produce this phenotype in an otherwise disomic genetic environment.

Several authors have reported impairments in prefrontal cortex (PFC) in Down syndrome that present a reduction in volume (Jernigan et al., 1993; Raz et al., 1995; Wisniewski, 1990) and a decrease in intrahemispheric and interhemispheric connectivity (Pujol et al., 2015). As a consequence of such impairments, PFC executive function and inhibitory behavioral control, which are the major contributing factors to intellectual disability, are compromised in Down syndrome individuals (Rowe et al., 2006; Ball et al., 2010; de Sola et al., 2015). However, the prefrontal physiology underlying such functional deficits has not yet been explored in Down syndrome mouse models.

Physiological features of cortical neurons and their synapses play a role in shaping the activation of the cortical network, with the balance between excitation and inhibition being a critical factor, and its impairment is accepted as one of the underlying causes of the cognitive deficits in Down syndrome (Eichler and Meier, 2008; Dierssen 2012). Dyrk1A is strongly expressed in the cerebral cortex (Martí et al., 2003), and its overexpression leads to defective cortical pyramidal cell morphology (Martinez de Lagran et al., 2012). However, to date, only few studies have suggested a direct link between Dyrk1A overexpression and the excitation/inhibition balance (Souchet et al., 2014), showing larger miniature EPSCs in prefrontal cortex slices of Dyrk1A transgenic mice (Thomazeau et al., 2014), but we do not know how these alterations would impact the global functionality of the prefrontal cortex network and the resulting properties of the emergent activity.

Here, we perform a detailed analysis of the prefrontal network emergent activity in vivo to detect possible neurophysiological alterations in a mouse model overexpressing Dyrk $1 A$ (TgDyrk1A). We found a decreased cortical excitability with decreased firing rate of cortical neurons and gamma frequency power in the prefrontal network of transgenic mice. We also identified reduced vesicular GABA transporter (VGAT) punctae on parvalbumin-expressing interneurons that suggest impaired modula-

de Economia y Competitividad Grants SAF2013-49129-C2-1-R and "Centro de Excelencia Severo 0choa 2013-2017" SEV-2012-0208, EU ERA-Net Neuron (F00D for THOUGHT), Secretaria de Universidades e Investigación del Departamento de Economía y Conocimiento de la Generalidad de Cataluña Grant SGR 2014/1125, and CIBERER (Centro de Investigación Biomédica en Red de Enfermedades Raras) (M.D.). We thank José María González Martín for technical support in surgeries with awake mice experiments.

${ }^{*}$ M.R.-M. and M.M.d.L. contributed equally to this work.

${ }^{\ddagger}$ M.V.S. -V. and M.D. are both senior authors.

The authors declare no competing financial interests.

Correspondence should be addressed to either of the following: Mara Dierssen, Dr. Aiguader 88, 08003 Barcelona, Spain, E-mail: mara.dierssen@crg.eu; or Maria V. Sanchez-Vives, Rosselló 149-153, 08036 BarceIona, Spain, E-mail: msanche3@clinic.ub.es.

DOI:10.1523/JNEUROSCI.2517-15.2016

Copyright $\odot 2016$ the authors $\quad 0270-6474 / 16 / 363649-12 \$ 15.00 / 0$ tion of inhibition. Using a computational model of the cortical network with recurrently connected excitatory and inhibitory neurons (Compte et al., 2003), we demonstrate that the reduced interneuron inhibition in TgDyrk1A mice would be sufficient to support the experimentally observed functional disturbances.

\section{Materials and Methods}

Animals. The production of mice transgenic for Dyrk $1 A$ (TgDyrk1A) has been described in detail previously (Altafaj et al., 2001). The transgene was inserted into C57BL/6JXSJL embryos (Charles River Laboratories) and the strain maintained by crossing wild-type (WT) and TgDyrk1A mice. The nontransgenic (WT) littermates served as controls. To visualize cortical pyramidal neurons, we also generated double transgenic mice (Thy1-YFP/TgDyrk1A) crossing TgDyrk1A mice with mice expressing yellow fluorescence protein (YFP) under the Thyl promoter (strain B6. Cg- $T g$ (Thy1-YFPH)2Jrs/J No. 003782; The Jackson Laboratories). Layer 5 pyramidal cells of the cerebral cortex of this murine model selectively express YFP. Same-sex littermates were group housed (three or four mice per cage) under a $12 \mathrm{~h}$ light/dark schedule (lights on at 9:00 A.M.) in controlled environmental conditions of humidity (60\%) and temperature $\left(22 \pm 2^{\circ} \mathrm{C}\right)$ with free access to food and water. Only males were tested in this study, and females were spared for breeding purposes. All experimental protocols involving the use of animals were performed in accordance with recommendations for the proper care and use of laboratory animals [local (law 32/2007) and European regulations (EU directive 86/609, EU decree 2001-486) and the Standards for Use of Laboratory Animals A5388-01 (NIH)] and were approved by the local ethical committees from Barcelona Biomedical Research Park, Hospital Clinic of Barcelona, and Pablo Olavide University.

In vivo extracellular recordings in anesthetized mice. Three- to 6month-old TgDyrk1A mice and their respective control littermates were used for extracellular recordings (Ruiz-Mejias et al., 2011). Anesthesia was induced with intraperitoneal injection of ketamine $(75 \mathrm{mg} / \mathrm{kg})$ and medetomidine $(1 \mathrm{mg} / \mathrm{kg})$. Atropine $(0.3 \mathrm{mg} / \mathrm{kg})$ was administered to avoid respiratory secretions. After tracheotomy, a maintenance dose of ketamine $(37.5 \mathrm{mg} / \mathrm{kg}$; i.p.) and methylprednisolone $(30 \mathrm{mg} / \mathrm{kg}$ ) was administered before placing the animal in the stereotaxic frame. Oxygen was delivered through a silicon tube placed $0.5-1 \mathrm{~cm}$ from the tracheal cannula. A continuous infusion of ketamine at $40 \mathrm{mg} / \mathrm{kg} / \mathrm{h}$ was delivered subcutaneously to maintain a constant level of anesthesia. Body temperature was maintained at $36-37.5^{\circ} \mathrm{C}$. Bilateral craniotomies were made in the medial prefrontal cortex [anteroposterior (AP), 2.3-2.5 mm from Bregma; lateral (L), $0.4 \mathrm{~mm}$; Franklin and Paxinos, 2008]. Extracellular slow wave recordings were obtained with tungsten electrodes with impedances of 1-2 $\mathrm{M} \Omega$, placed in deep layers $(0.4 \mathrm{~mm}$ lateral and $1.0-1.2$ $\mathrm{mm}$ deep). The signal was digitized at $20 \mathrm{kHz}$ and recorded (CED and Spike 2 software; Cambridge Electronic Design).

In vivo slow wave propagation. Silicon probes of 16 aligned electrodes separated by $100 \mu \mathrm{m}$ (Neuronexus) were used to record activity propagation. Craniotomies of $1.5 \times 2 \mathrm{~mm}$ were performed to record from frontal (AP 1.5 to 3.2, L 0.4, 1.1-1.2 mm deep) or motor areas (AP, -0.5 to $1.5 \mathrm{~mm}$; L, 1-1.5 mm; 0.9-1.2 $\mathrm{mm}$ deep). We computed the speed of UP state propagation across the cortex, relying on the time lags between consecutive detected UP state onsets from multiunit activity (MUA) of different electrodes. UP state onsets detected in the MUA from all the electrodes within the $150 \mathrm{~ms}$ time windows were considered to belong to the same wavefront. The array of time lags $\delta_{n=1.16}$ between such onsets and the average onset time across electrodes determined the propagation mode of slow waves. Propagation modes were sorted out by performing a principal component analysis on time lag arrays. For each animal, at least $n=300$ consecutive UP states were used for activity propagation analysis (Ruiz-Mejias et al., 2011).

Electrophysiological recordings from awake mice. Animals were anesthetized with intraperitoneal injection of chloral hydrate $(0.1 \mathrm{ml} / 10 \mathrm{~g})$ and implanted with bipolar recording electrodes aimed at the right prefrontal cortex area (AP $1.94 \mathrm{~mm}$; L $0.3 \mathrm{~mm} ; 1.6 \mathrm{~mm}$ deep, prelimbic cortex; Franklin and Paxinos, 2008). These electrodes were made of $50 \mu \mathrm{m}$ thick, Teflon-coated tungsten wire (Advent Research Materials). A bare silver 
wire $(0.1 \mathrm{~mm})$ was affixed to the skull as a ground. Wires were connected to a four-pin socket (RS Amidata) fixed to the skull with screws and dental cement (for additional details of this chronic preparation, see Gruart et al., 2006). Local field potential (LFP) recordings were obtained from freely moving animals in a square plastic box of $18 \times 10 \times 9 \mathrm{~cm}$. The box was closed with a cover with a hole allowing the pass of wires and placed in a sound-attenuating chamber $(90 \times 55 \times 60 \mathrm{~cm})$, which was constantly illuminated ( $3 \mathrm{~W}$ lamp). Spontaneous cortical activity was recorded from each mouse once a day for $5 \mathrm{~min}$, during $10 \mathrm{~d}$. The signal was amplified with a Grass P511 AC amplifier and digitized at $20 \mathrm{kHz}$ with an acquisition board (CED and Spike 2 software; Cambridge Electronic Design).

Electrophysiological data analysis. MUA was estimated as the power of recorded raw signals (unfiltered electric field probed by intracranial recordings) in the high frequency band $[0.2,1.5 \mathrm{kHz}]$ obtained from moving windows of $5 \mathrm{~ms}$. Logarithmically scaled MUA was smoothed with a moving average on $40 \mathrm{~ms}$ time windows. Resulting bimodal histograms of smoothed log (MUA) allowed identifying the optimal threshold (60\% of the distance between the two peaks corresponding to DOWN and UP states) to single out DOWN to UP and UP to DOWN transitions. The relative firing rate was taken as the MUA value of the peak corresponding to UP states after normalizing MUA to be zero during DOWN periods. Detected transitions were used to compute the statistics of UP and DOWN state durations and upward transition slope, as well as to characterize propagation modes of traveling waves in multielectrode recordings (for details, see Reig et al., 2010; Sanchez-Vives et al., 2010; Ruiz-Mejias et al., 2011). Power spectral density was estimated relying on a standard Welch's method. Beta and gamma frequency band quantification in UP states were assessed as described by Ruiz-Mejias et al. (2011). All MUA off-line estimates and analyses were implemented in MATLAB (The MathWorks).

Immunohistochemistry. Eight WT and eight TgDyrk1A mice were anesthetized and transcardially perfused with $0.1 \mathrm{~m}$ PBS followed by chilled $4 \%$ paraformaldehyde in PBS. Brains were removed from the skull and post fixed in the same fixative for $24 \mathrm{~h}$ at $4^{\circ} \mathrm{C}$ overnight. After rinsed in PBS, brains were cryoprotected in $30 \%$ sucrose and kept frozen at $-80^{\circ} \mathrm{C}$. Coronal sections, $40 \mu \mathrm{m}$ thick, were sliced with a cryostat and maintained in cryoprotective solution at $-20^{\circ} \mathrm{C}$ until used. Free floating coronal sections containing the PFC (Franklin and Paxinos, 2008) were selected. Background staining was blocked with PBS containing $0.2 \%$ Triton X-100, $3 \%$ bovine serum albumin, and $0.2 \mathrm{~m}$ glycine $1 \mathrm{~h}$ at room temperature. Sections were incubated overnight at $4^{\circ} \mathrm{C}$ with primary antibodies and after several washes with $0.1 \mathrm{M}$ PBS, incubated for $1 \mathrm{~h}$ at room temperature with the corresponding fluorescence conjugated secondary antibodies (Alexa 488 or 594, 1:500; Promega). Finally, sections were incubated 10 min with Hoechst solution (1:1000; Sigma) for nuclei staining. Sections were mounted and coverslipped with Mowiol reagent. To characterize subpopulations of interneurons, we used antiparvalbumin (1:1500; Sigma), anti-calretinin (1:1000; Sigma), and antisomatostatin (1:500; Millipore) antibodies. We also used anti-vesicular glutamate transporter (anti-VGLUT1, 1:200; Synaptic Systems) and anti-VGAT (1:200; Synaptic Systems) antibodies to detect excitatory and inhibitory presynaptic vesicles, respectively. Excitatory and inhibitory postsynaptic sites were detected using anti-PSD-95 (1:800; Abcam) and anti-Gephyrin (1:1000; Synaptic Systems) antibodies, respectively.

Confocal microscopy and image analysis. Images were acquired with a confocal Leica TCS SPE microscope and analyzed with ImageJ software. For the analysis of the different subpopulations of interneurons, microphotographs were taken from the PFC using a $10 \times$ lens. Images for the analysis of presynaptic and postsynaptic markers were obtained using a $63 \times$ lens with a $5 \times$ zoom. Excitatory-inhibitory balance was calculated as described previously (Blundell et al., 2009).

Statistical analysis. Experiments were not performed blind to genotype, but because data acquisition was automated, this does not affect data processing and analysis. The general criteria of exclusion were preestablished, and samples with a value that differed by more than two SDs from the mean were excluded from the analysis. The statistical tests used in each experiment were appropriate to the type of data. Normal distribution of data and homogeneity of variances was assessed using Shapiro-
Table 1. Synaptic conductance $g_{\text {syn }}$ and reversal potential $V_{\text {syn }}$ on excitatory $(E)$ and inhibitory $(I)$ neurons

\begin{tabular}{lcll}
\hline & $V_{\text {syn }}(\mathrm{mV})$ & $g_{\text {syn }}$ on $E(\mathrm{nS})$ & $g_{\text {syn }}$ on $/(\mathrm{nS})$ \\
\hline AMPA & 0 & 0.30 & 0.12 \\
NMDA & 0 & 4.00 & 0.80 \\
GABA $_{\mathrm{A}}$ & -75 & 7.50 & 2.52 \\
\hline
\end{tabular}

The NMDA synaptic conductance has an additional voltage dependence, governed by the extracellular magnesium concentration $\left[\mathrm{Mg}^{2+}\right]=1 \mathrm{mM}$, that is introduced here by dividing $g_{\mathrm{NMDA}}$ by the function $1+\left[\mathrm{Mg}^{2+}\right] \exp$ $(-0.062 *$ V)/3.57 (Jahr and Stevens, 1990).

Wilk and Levene tests, respectively. Comparisons of means were performed using two-tailed Student's $t$ test or repeated measures ANOVA. For repeated measures ANOVA, the sphericity assumption was assessed using Mauchly's test, and when not achieved, Greenhouse correction was taken. Wilcoxon's and Mann-Whitney $U$ tests were used for awake and propagation analyses as specified in the text. Data are presented as means \pm SE.

Computational model. We developed a computational model of a local cortical circuit with pyramidal cells and fast-spiking interneurons, incorporating NMDA, AMPA, and GABA synaptic kinetics. We built a neural network from a conductance-based model of single excitatory and inhibitory neurons described previously by Compte et al. (2003) using the same parameters for the dynamics of the ionic channels and the membrane potential as well as the connectivity pattern. All neurons receive an extra train of excitatory presynaptic potentials representing the synaptic current coming from areas other than the explicitly modeled neuronal network. The externally incoming action potentials followed an heterogeneous Poisson process with an instantaneous event rate generated according to an Ornstein-Uhlenbeck process with a relaxation time of 16 ms and amplitude of 100 spikes/s (Gillespie, 1996). The average event rate is set to $50 \mathrm{~s}^{-1}$, and the corresponding AMPA and NMDA conductance are equal to those shown in Table 1.

The electrical activity $E(t)$ of the in silico neural network is modeled according to the work of Mazzoni et al. (2008) as an equivalent measure of the electrophysiological LFP recordings: $E(t)=\left\langle\left|I_{\mathrm{AMPA}}\right|+\left|I_{\mathrm{NMDA}}\right|+\right.$ $\left.\left|I_{\mathrm{GABA}}\right|\right\rangle$, where the average only takes into account the synaptic currents impinging on the excitatory neurons at each time window. We evaluated the effects of varying inhibitory and excitatory contacts on fast-spiking interneurons and pyramidal cells.

\section{Results}

Firing rate and regularity of the slow rhythm are decreased in prefrontal cortex of TgDyrk1A mice

We first proceeded to a detailed analysis of the emergent activity patterns to identify potential functional alterations. The PFC of both WT $(n=15)$ and TgDyrk1A $(n=16)$ anesthetized mice displayed consistent slow oscillations (Ruiz-Mejias et al., 2011; Stroh et al., 2013). Slow oscillations consisted of periods of activity or UP states interspersed with silent periods or DOWN states (Fig. 1A,B). The duration of UP and DOWN states and their coefficient of variation $(\mathrm{CV})$, state transition slopes, and relative firing rate were compared between WT and TgDyrk1A mice using two-tailed Student's $t$ test. No differences were detected in the frequency of oscillations, whose average was $0.88 \mathrm{~Hz}$ in both genotypes (Fig. 1C). The duration of UP and DOWN states was also preserved in transgenic mice [UPs, $0.32 \pm 0.07 \mathrm{~s}(\mathrm{WT})$ and $0.33 \pm 0.08 \mathrm{~s}(\mathrm{TG})$; Fig. $1 D$; DOWNs, $0.93 \pm 0.36 \mathrm{~s}$ and $0.87 \pm$ 0.24 s; Fig. $1 E]$. TgDyrk1A mice showed an increase in the CV of the UP state durations in the PFC $(t=-2.06, \mathrm{df}=29, p=0.049$; Fig. $1 F)$, suggesting a decreased regularity in the UP states. This is particularly relevant because PFC has a higher regularity of slow waves than other cortical areas (Ruiz-Mejias et al., 2011) and a leading role in the initiation of slow waves in humans (Massimini et al., 2004) and mice (Ruiz-Mejias et al., 2011; Stroh et al., 2013). However, no significant alterations were found in the $\mathrm{CV}$ of 
A
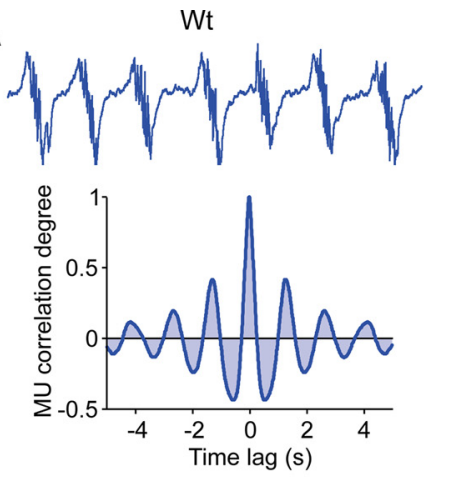

B

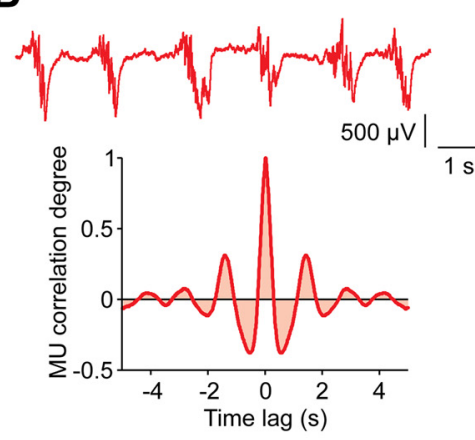

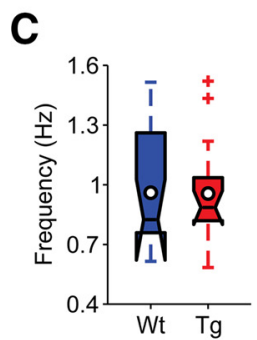

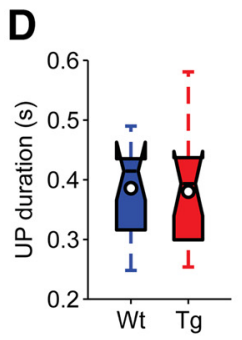

H

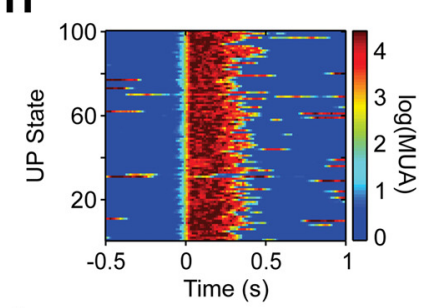

|

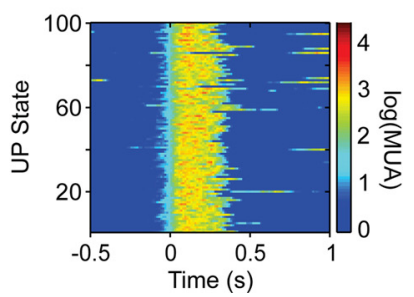

E

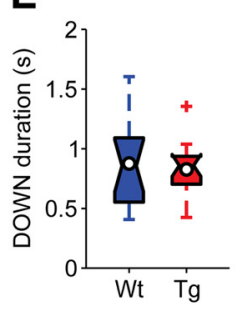

Wt

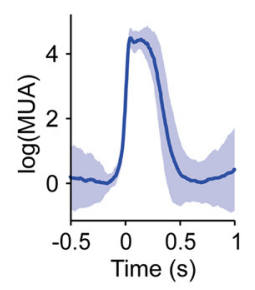

$\operatorname{Tg}$

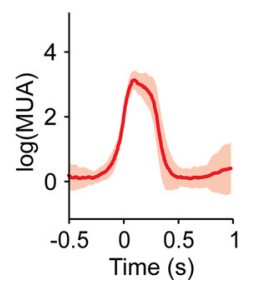

G

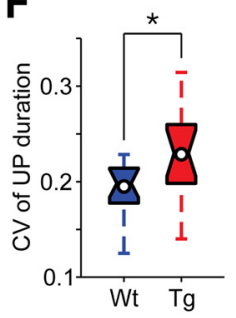

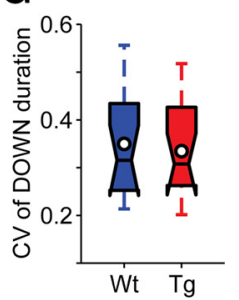

J

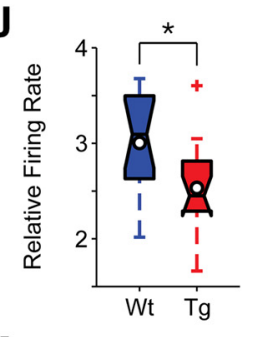

K

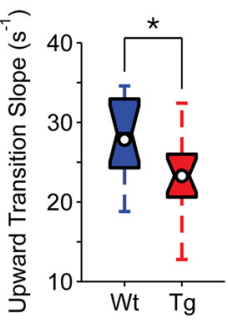

Figure 1. Quantification of slow oscillatory activity in the PFC of anesthetized TgDyrk1A and WT mice. $A, B$, Top, Raw traces of the slow oscillation recorded in WT and TgDyrk $1 A$ mice, respectively. Bottom, Autocorrelations of the raw traces in both genotypes. $\mathbf{C}-\mathbf{G}$, Temporal parameters of the slow oscillations resulting from the analysis of MUA in both groups of mice. A significant difference $(p<0.05)$ was found in the coefficient of variation of UP state durations. $\boldsymbol{H}-\boldsymbol{K}$, Parameters regarding the firing properties of PFC network of both genotypes. $\boldsymbol{H}, \boldsymbol{I}$, Example cases illustrating the methodology and the most significant differences between TgDyrk1A and WT mice. Left, Raster plots of 100 UP states. Relative firing rates are color coded [log(MUA); see Materials and Methods]. Right, Average peristimulus histogram of $\log (\mathrm{MUA})$ from the raster plot on the left. The shades correspond to the SD (WT, $n=15 ; \operatorname{TgDyrk} 1 A, n=16)$. J, Comparison of the population "relative firing rate" $[\log (\mathrm{MUA})$; see Materials and Methods] during UP states. $\boldsymbol{K}$, Comparison of the population upward transition slopes of $\log (\mathrm{MUA})$ from DOWN to UP states. Filled box plots depict the first and third quartiles with the median (center black line). Center white circles represent mean values. Whiskers extend to extreme values, excluding outliers (crosses). Outliers are data values exceeding the nearest quartile by 1.5 times the distance between first and third quartiles. ${ }^{*} p<0.05$, Student's $t$ test.

DOWN state durations (Fig. $1 G$ ), or in the CV of the complete cycle (UP and DOWN states; result not shown), revealing that the alteration of rhythmicity is only partial.

Significant differences emerged in the firing rate of the network $(t=2.72, \mathrm{df}=29, p=0.011)$, the population firing rate being lower during UP states in TgDyrk1A mice compared to WTs (Fig. $1 H-J$ ). The slope of the transition from DOWN to UP states of the firing rate (upward transition slope) was also significantly lower in TgDyrk1A mice $(t=2.47, \mathrm{df}=29, p=0,019)$, revealing a slower recruitment of the network (Fig. $1 K$ ). No changes were detected for the UP to DOWN transition (result not shown). The decreased firing rates during UP states would be compatible with a more inhibited network.

\section{Decreased gamma oscillations in the prefrontal cortex} of TgDyrk1A

During UP states the local cortical activity is synchronized in fast beta $(15-30 \mathrm{~Hz})$ and gamma $(30-90 \mathrm{~Hz})$ frequencies (Steriade and Amzica, 1996; Hasenstaub et al., 2005; Compte et al., 2008; Ruiz-Mejias et al., 2011). To quantify the high frequencies during slow oscillations, we computed Fourier analyses in UP and DOWN states in WT $(n=15$; Fig. $2 A)$ and TgDyrk1A $(n=16$; Fig. $2 B$ ) anesthetized mice. We measured the generation of high frequencies in two bands: beta $(20-30 \mathrm{~Hz})$ and gamma $(30-90$ $\mathrm{Hz}$ ). The power was first calculated for UP and DOWN states separately (Fig. $2 A-C$, left). No differences were detected between WT and TgDyrk1A mice in the beta/gamma power in DOWN 
A

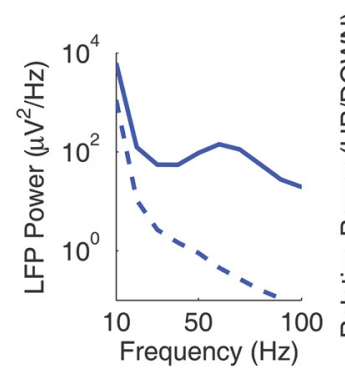

C

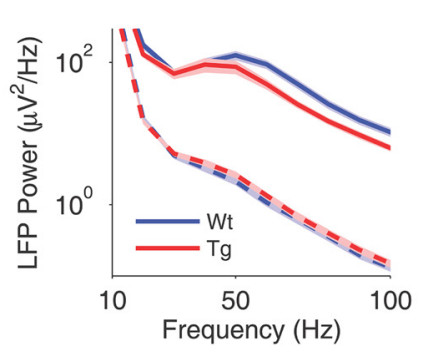

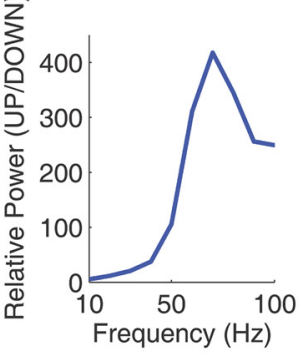

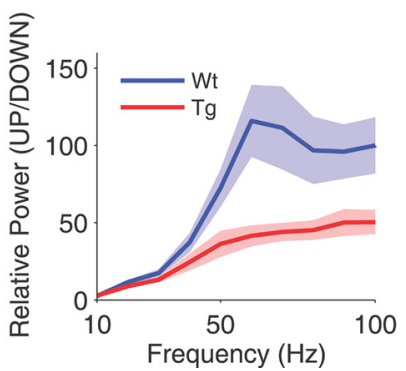

B

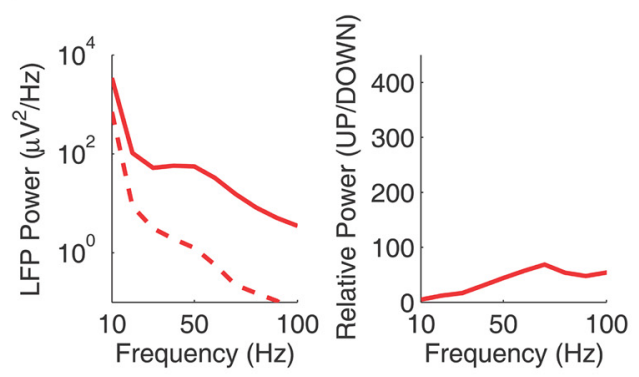

D

Figure 2. Decrease in gamma frequencies in the prefrontal cortex of $T g D y r k 1 A$ mice. $A$, Representative example of a WT (blue) case. Left, The power spectral density in UP (continuous line) and DOWN (discontinuous line) states. Right, The relative power (UP/DOWN). B, Representative example of a TgDyrk1A (red) case. Left, Power spectral density in UP (continuous line) and DOWN (discontinuous line) states. Right, Relative power (UP/DOWN). C, Population average of the power spectrum; shades depict SEM. Left, Power spectral density in UP (continuous line) and DOWN (discontinuous line) states in both WT (blue) and TgDyrk1A (red) mice. Right, Relative power (UP/DOWN) in WT (blue) and TgDyrk1A (red) mice. D, Box plots of the relative power in beta (20 -30 Hz) and gamma $\left(30-90 \mathrm{~Hz}\right.$ ) bands in both genotypes (WT, $n=15 ; \operatorname{TgDyrk} 1 A, n=16$ mice). Filled box plots depict the first and third quartiles with the median (center black line). ${ }^{*} p<0.05$, Mann-Whitney U test.

states (Fig. 2C, left). We next calculated the relative UP/DOWN power for quantification (Fig. $2 A-C$, right). We found that the power in gamma was significantly lower in TgDyrk1A than in WT mice (Mann-Whitney U test, $Z=2.23, p=0.025$; Fig. $2 D$ ), while the power in beta did not change.

\section{The propagation of slow waves is altered in the motor cortex of TgDyrk1A mice}

In humans, slow waves during sleep are mainly generated in frontal cortex, traveling toward more posterior areas (Massimini et al., 2004; Nir et al., 2011). Such preferred backward propagation of slow oscillations is observed also in anesthetized mice when probed both with multielectrode recordings (Ruiz-Mejias et al., 2011) and voltage-sensitive dye imaging (Stroh et al., 2013). Traveling waves are an emergent property of spatially organized neuronal networks and can be affected by changes in the underlying circuitry. Hence, we looked for differences of propagation between WT $(n=18)$ and TgDyrk1A $(n=20)$ anesthetized mice in a wide frontal area comprising the PFC and motor cortex, where onset and propagation of slow waves are likely to be observed, respectively.

The passage of a wavefront across the area covered by the electrode array appeared as a sequence of UP state onsets with progressively changing time lags $\delta_{n}$ (Fig. $3 A, B$ ). Modes of propagation changed from one UP state to another, showing slow waves traveling both backward (increasing $\delta_{n}$; Fig. $3 A$ ) and forward (decreasing $\delta_{n}$; Fig. $3 A$ ) with respect to the anterior-posterior axis parallel to 16 aligned electrodes. Grouping similar patterns of activation onsets, the mean and variability of inverse speeds (time over space) of propagation were computed for each of these groups (Fig. $3 B, C$ ). Pooling all inverse speeds measured in motor cortex (Fig. 3D) shows that slow waves appear to travel preferentially from front to back (positive speeds, sign test, $t_{(60)}=$ $234, Z=-5.0, p<10^{-6}$ ), whereas a preferred direction of prop- agation is not apparent in PFC (Fig. 3E) in either genotype (sign test, $\left.t_{(30)}=152, Z=-1.7, p=0.098\right)$. The balance between positive and negative speeds in PFC further suggests that slow waves initiate their journeys in a frontal region around the electrodes location. A progressive reduction of cortical excitability of frontal areas appeared to underlie the significant reduction of backward propagation speed across motor cortex in TgDyrk1A mice $(19.4 \pm 2.1 \mathrm{~mm} / \mathrm{s})$, compared to WT animals $(29.7 \pm 3.9$ $\mathrm{mm} / \mathrm{s}$; Mann-Whitney $U$ test, $U_{(60)}=2350, Z=2.50, p=0.012$ ). The loss of excitability slowing the speed of propagation can be explained by an increase of inhibition in cortical networks, as discussed in the Results section.

\section{Firing rate and gamma power in the prefrontal cortex of the awake mouse}

In the anesthetized TgDyrk1A mouse we found a significant decrease in the network firing rate during UP states in the prefrontal cortex, along with a decreased in gamma frequencies. These alterations of the emergent activity, together with others such as the increased variability in the UP/DOWN dynamics, strongly suggested that some basic mechanisms of network reverberation were altered in TgDyrk1A with respect to WT mice. We recorded spontaneous cortical emergent activity during anesthesia based on the hypothesis that such activity reflects functional features of the underlying cortical network. However, to further make this finding extensive to the awake state, we next recorded from the prefrontal cortex of chronically implanted awake mice while they

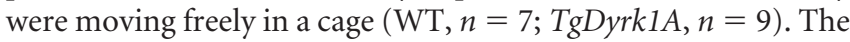
analysis of the baseline activity revealed a significant decrease in the maximum network firing rate in TgDyrk1A mice (Fig. 4B; Mann-Whitney $U$ test, $\left.U_{(58)}=1630, Z=2.27, p=0.023\right)$, in agreement with the changes observed in the anesthetized animal. Furthermore, the power in the gamma range $(30-100 \mathrm{~Hz})$ was also lower in the TgDyrk1A mice than in WTs (Fig. 4A,C,D; 

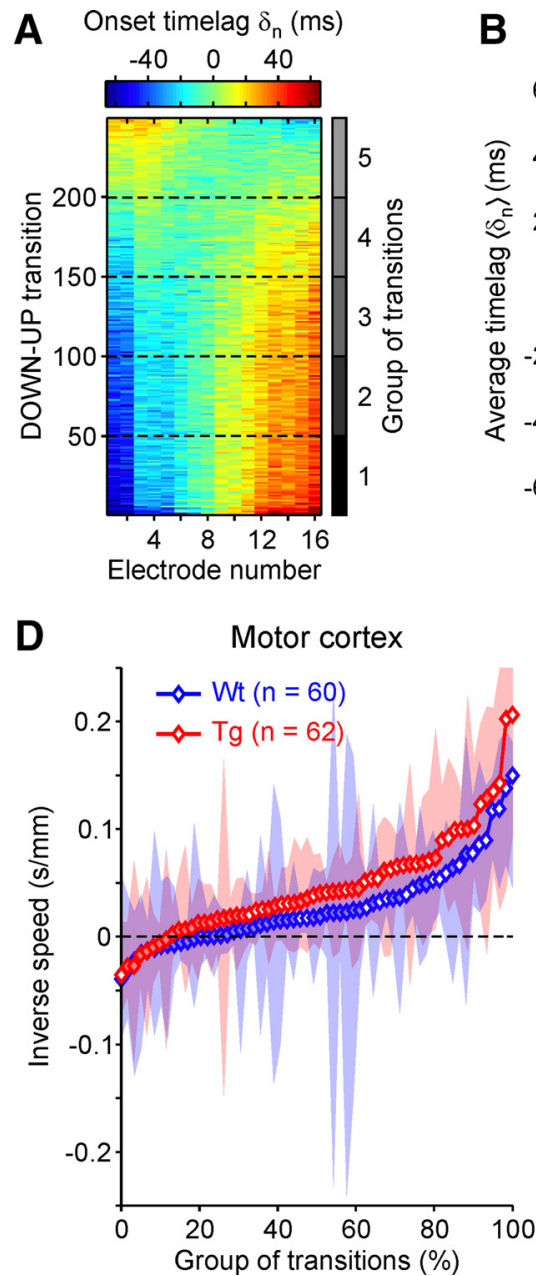
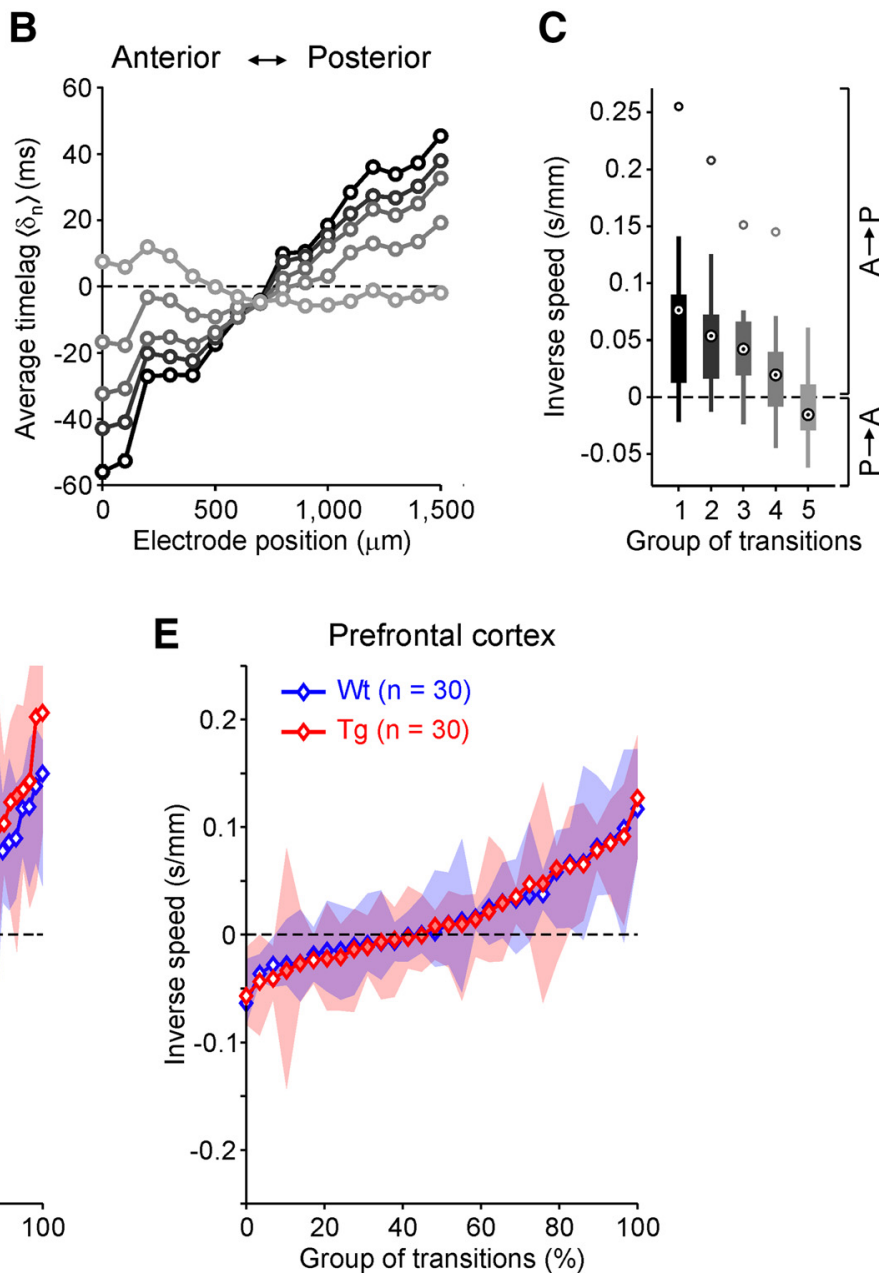

Figure 3. Slow wave propagation across frontal cortex of WT and TgDyrk1A mice. $A$, Matrix of time lags $\delta_{n}$ of UP state onsets simultaneously detected in 16 aligned electrodes from an example recording in motor cortex. Matrix rows are different DOWN to UP transitions, and colors code for $\delta_{n}$. Principal component analysis is used to sort DOWN-UP transitions, bringing together similar modes of slow wave propagation. $\boldsymbol{B}$, UP state onsets are pooled in five equally sized groups of transitions (dashed lines in $\boldsymbol{A}$ ), and group averaged $\delta_{n}$ are plotted for each of them (gray levels as in vertical color bar of $\boldsymbol{A}$ ). $\boldsymbol{C}$, Statistics of inverse local speeds in the five propagation modes in $\boldsymbol{B}$. For each mode, the 15 inverse local speeds are the differences between average $\delta_{n}$ in nearby electrodes divided by their distance. Black circles with a dot are means of inverse speeds. Thick bars represent first and third quartiles, thin lines represent extreme values, and gray circles represent outliers (as in Fig. 1). $\boldsymbol{D}, \boldsymbol{E}$, Mean inverse speeds in all groups of transitions detected in motor ( $\boldsymbol{D})$ and prefrontal $(\boldsymbol{E})$ cortex of both WT (blue, $n=18)$ and TgDyrk1A (red, $n=20)$ mice. Shaded areas show first and third quartiles of inverse local speeds in each group of transitions. Propagation modes are sorted by inverse speeds. Symbols representing means are white filled if the inverse speed of the propagation mode is significantly different from 0 (Wilcoxon's test, $p<0.05$ ).

Mann-Whitney $U$ test performed for each sampled frequency $\omega / 2 \pi, p<0.05$; note that $p<0.05$ refers to the gray vertical strip, where $p$ is different at each Fourier frequency). We conclude that both firing rate and gamma frequencies are significantly decreased in awake $T g D y r k 1 A$ mice, a feature that is compatible with a more inhibited network.

Excitatory-inhibitory balance in $T g D y r k 1 A$ prefrontal cortex Our neurophysiological results suggested overinhibited PFCs in TgDyrk1A mice. Parvalbumin, calretinin, and somatostatin immunostaining revealed no differences in the number of cortical GABAergic neurons in the PFCs of TgDyrk1A mice $(n=8)$ compared to WT mice ( $n=8$; Fig. $5 A$ ). We also analyzed excitatory (VGLUT1) and inhibitory (VGAT) presynaptic punctae in the PFC. TgDyrk1A mice showed a significantly increased VGLUT1/ VGAT ratio (two-tailed Student's $t$ test, $t=-2.61$, df $=15, p=$ 0.020 ; Fig. $5 B$ ), due to a reduced number of VGAT inhibitory punctae (two-tailed Student's $t$ test, $t=2.38, \mathrm{df}=15, p=0.031$ ), with no differences in VGLUT1 (Fig. 5C,D). No differences were found in the number of postsynaptic inhibitory sites stained with
anti-Gephyrin antibody (Fig. 5E) or excitatory sites (PSD-95) in transgenic mice (Fig. 5F) compared to WTs.

To explore whether VGLUT1 or VGAT punctae were differentially altered in specific neuronal subpopulations, we used double transgenic Thy-YFP/TgDyrk1A mice to directly visualize cortical pyramidal neurons. We did not detect differences in the density of the excitatory (VGLUT1 + ) or inhibitory (VGAT+) inputs received by pyramidal neuron somas in Thy-YFP/ TgDyrk1A mice (Fig. 5G,H).

Importantly, parvalbumin positive fast-spiking interneurons that modulate oscillatory activity in the gamma range (Bartos et al., 2007; Whittington et al., 2011) received significantly fewer inhibitory terminals (VGAT+ punctae) in TgDyrk1A compared to WT mice (two-tailed Student's $t$ test; $t=2.55$, df $=8, p=$ 0.034 , Fig. $5 I, J)$, indicating a decreased inhibitory control of the main inhibitory population of PFC. The density of excitatory presynaptic terminals (VGLUT1+ punctae) contacting parvalbumin positive neurons was equal in both genotypes (Fig. 5I). We conclude that overexpression of Dyrk1A leads to a reduction of the inhibitory synapses received by parvalbumin interneurons, 
A
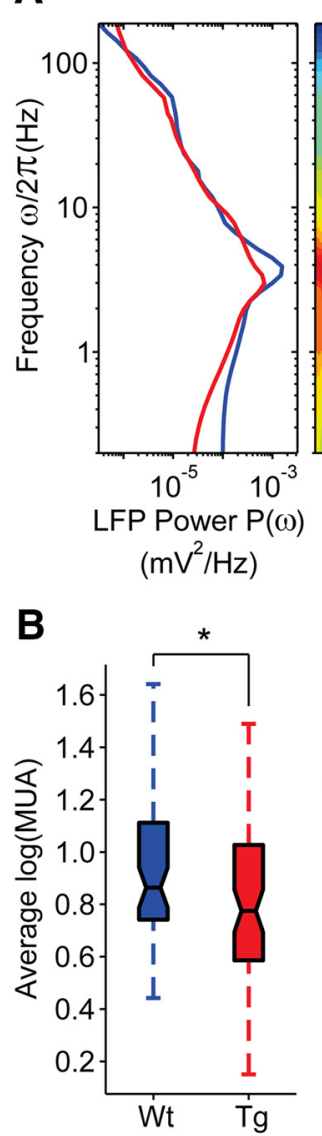

Wildtype

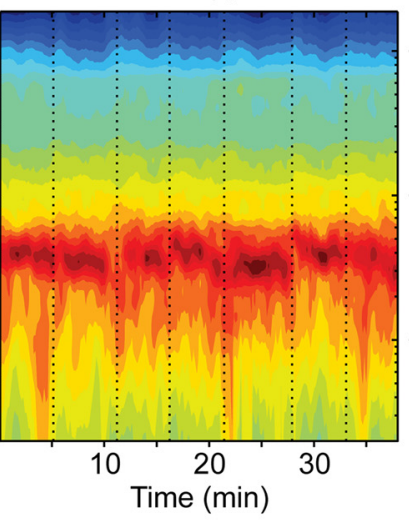

C

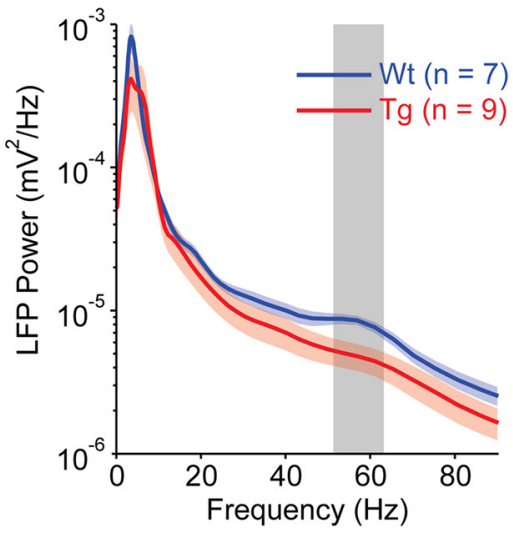

Transgenic

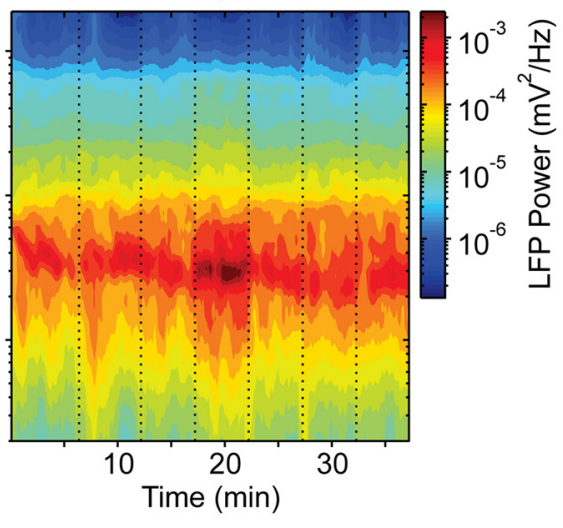

D

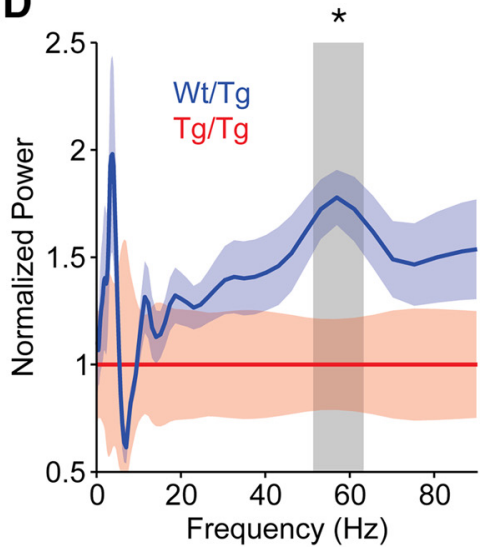

Figure 4. PFC spontaneous activity in the awake TgDyrk1A and WT mice. $\boldsymbol{A}$, Raw signal from chronically implanted electrodes are recorded in different experimental sessions from consecutive days. Awake animals were placed in transparent boxes without performing any particular task (see Materials and Methods). Spectrograms of the unfiltered field potentials are shown on the right for representative WT (left) and TgDyrk1A (right) mice. Vertical dotted lines mark daily recording sessions. Left, Power spectra P $(\omega)$ resulting from the average in time of the spectrograms. Red and blue curves are for TgDyrk1A and WT mice, respectively. B, Box plot of the mean log (MUA), a value proportional to the local network firing rate, was measured in all recording sessions (WT, $n=58$; $\mathrm{Tg}, n=73$, average of 8.2 sessions per animal). In WT mice, the firing rate was significantly larger than the activity measured in $T g D y r k 1 A$ mice $(p<0.05)$. $C$, Grand average $P(\omega)$ across animals, solid curves. Shaded strips show the SEM. The legend shows the included numbers of animals. The gray region is the frequency band where the average spectra are significantly different $(p<0.05$ ). D, Relative power spectra computed as the ratio between $\mathrm{P}(\omega)$ in the WT and the average spectrum $\mathrm{P}(\omega)$ in $\operatorname{TgDyrk1A}$ mice. ${ }^{*} p<0.05$, Mann-Whitney $U$ test.

which may functionally result in a disinhibition of this inhibitory population and therefore a local overinhibition of the neuronal network.

\section{Proposed mechanism for the reduction of the firing rate and gamma synchronization in TgDyrk1A mice}

The experimental observations described so far in TgDyrk1A mice show that Dyrk1A overexpression leads to (1) a decrease in gamma power in PFC of awake animals, and (2) a reduction of the inhibitory synapses acting upon inhibitory interneurons. To explore a potential causal link between these two effects, we developed a neuronal network model based on the one published in (Compte et al., 2003) that describes the cortical dynamics during spontaneous slow oscillations. This model allowed us to test how the emergent network dynamics varied when the connectivity of the neuronal population was modified, according to the results obtained in TgDyrk1A mice. In the model, the spontaneous firing of excitatory neurons recruits the local network through AMPA and NMDA synaptic connections, leading to the UP state. The local inhibitory population is also recruited, and there is GABAergic innervation over both excitatory and inhibitory neurons. Spike-frequency adaptation driven by the buildup of $\mathrm{K}^{+}$ channels terminates the UP state, leading to the silent DOWN state. Through these mechanisms (recurrency and adaptation mechanisms), the model replicates the slow oscillation pattern (Fig. 6B) as in the study by Compte et al. (2003).

A population-based network diagram representing the WT and TgDyrk1A mice is given in Figure $6 A$ (blue and red, respectively). Our analogous in silico model of the TgDyrk1A mice considers a $35 \%$ reduction change in the number of inhibitory contacts on inhibitory neurons, similar to the results shown in Figure 5I.

As detailed in Materials and Methods, the model produces an LFP signal that represents the collective synaptic activity impinging on the excitatory population. The alignment of the dendritic arbor of pyramidal neurons through distinct columns has suggested that those cells are the major contributors to the LFP (Makarov et al., 2010; Beim Graben and Rodrigues, 2012). In agreement with the experimental results obtained, in the network reported by Compte et al. (2003, 2008), the UP state shows a prominent local peak within the gamma band $(30-90 \mathrm{~Hz})$ with respect to the DOWN state, which exhibits a noisy $1 / \mathrm{f}$ profile (Bédard and Destexhe, 2009). In the model, the reduction in the inhibitory-inhibitory connections was enough to decrease the neuronal firing rate (Fig. 6C) and the oscillatory power mainly within the gamma band (Fig. 6D). Note that the scale of the 
A

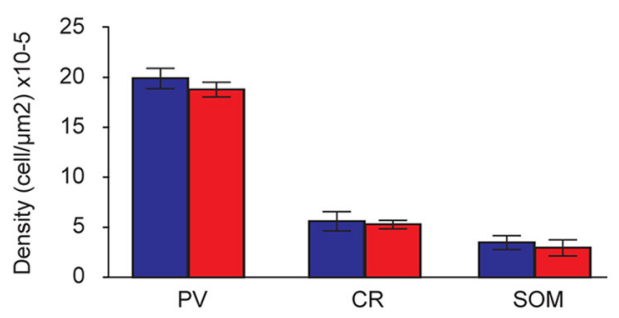

D
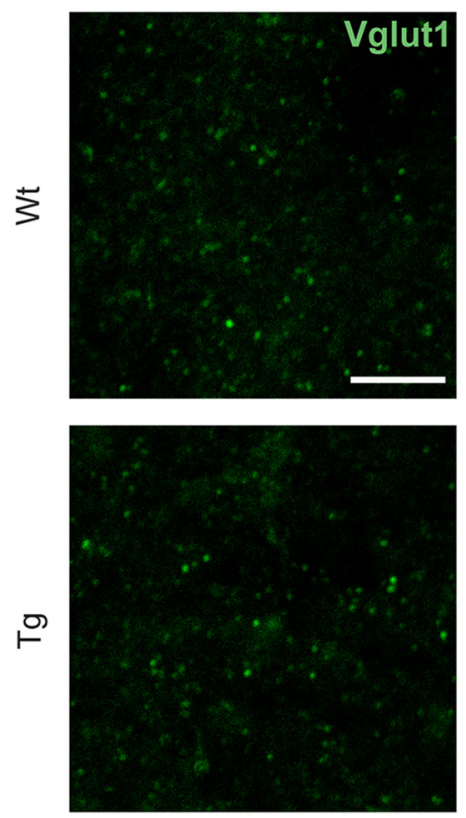

G

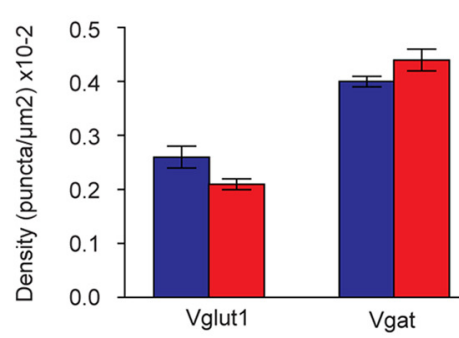

I

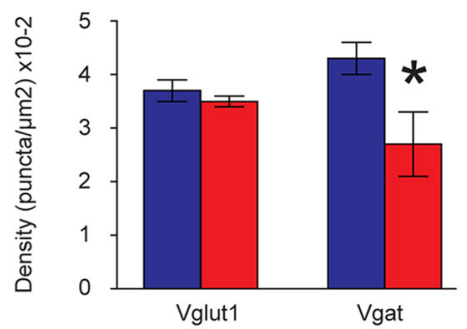

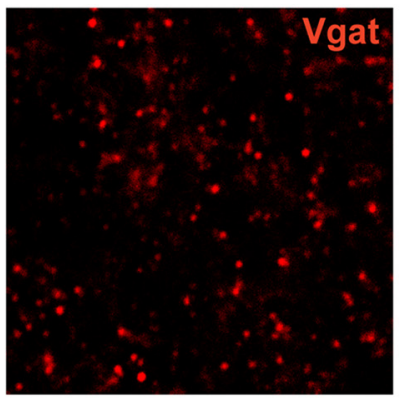

B
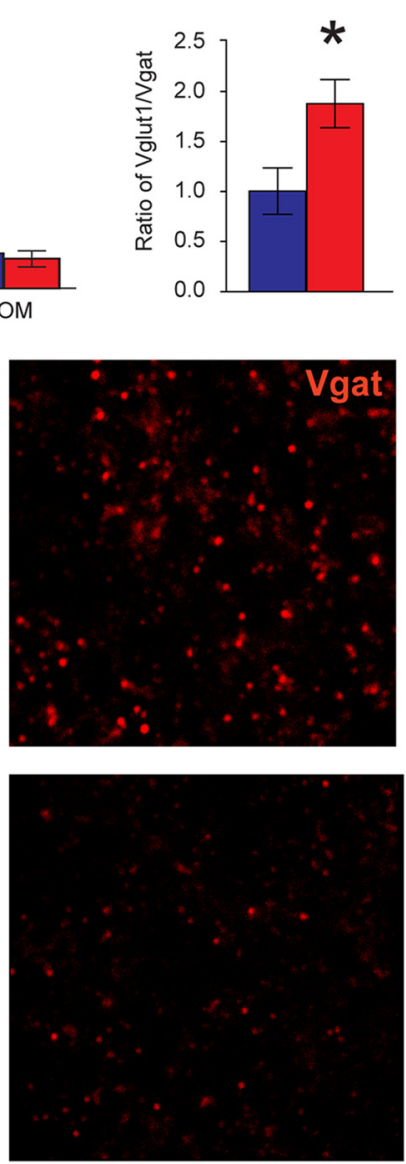

H
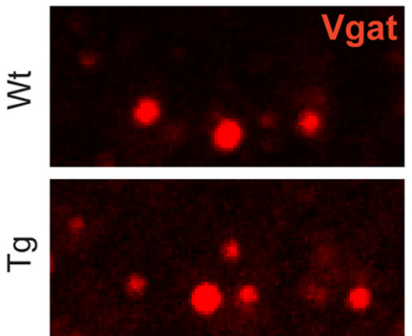

J
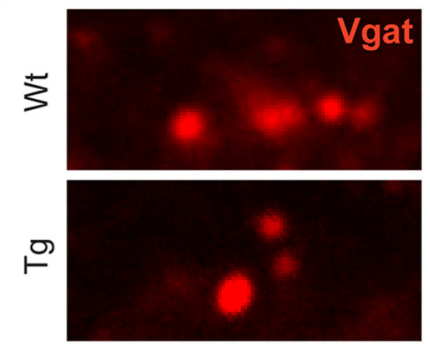

C

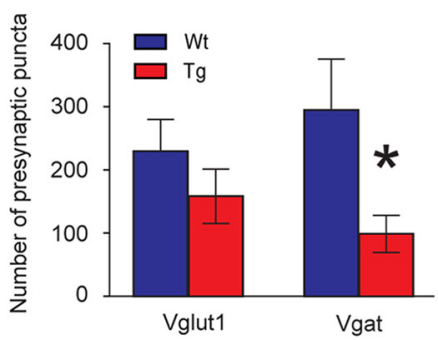

E

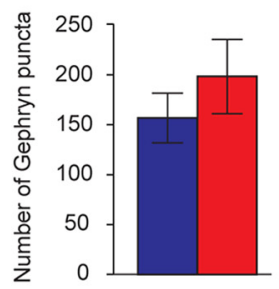

F

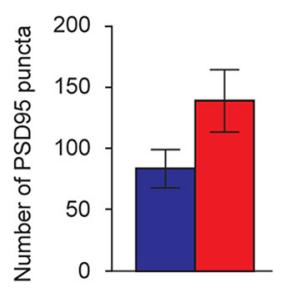

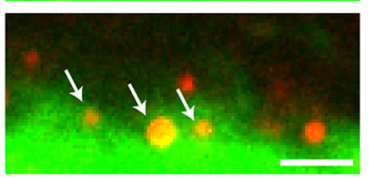
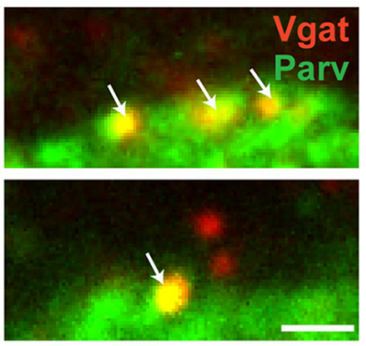

Figure 5. Histological analysis of the PFCs of TgDyrk1A mice. $A$, Density of the different inhibitory neuronal populations represented by the parvalbumin (PV), calretinin (CR), and somatostatin (SOM) positive cells in the PFC. B Ratio of the vesicular VGLUT1 (excitatory) versus VGAT (inhibitory) presynaptic markers as an index of the excitatory-inhibitory balance. $\boldsymbol{C}$, Number of presynaptic inhibitory and excitatory punctae in the PFC. $\boldsymbol{D}$, Confocal images showing VGLUT1 (green) and VGAT (red) punctae in WT (top) and TgDyrk1A (bottom) PFC. $\boldsymbol{E}$, $\boldsymbol{F}$, Number of postsynaptic inhibitory (Gephyrin; $\boldsymbol{E}$ ) and excitatory (PSD-95; $\boldsymbol{F}$ ) sites. $\mathbf{G}$, Density of excitatory and inhibitory terminals contacting with excitatory pyramidal neurons. $\boldsymbol{H}$, Single confocal images illustrating inhibitory terminals (red) contacting the soma of pyramidal neurons (green) in WT (top) and TgDyrk1A (bottom) PFC. I, Density of excitatory and inhibitory terminals contacting with parvalbumin positive neurons.J, Representative confocal images of inhibitory perisomatic contacts (red) on parvalbumin positive neurons (green) of WT (top) and TgDyrk1A (bottom) PFC. Blue bars represent WT mice, and red bars represent TgDyrk1A mice. Scale bars: $D, 5 \mu \mathrm{m} ; \boldsymbol{H}, \boldsymbol{J}, 1 \mu \mathrm{m}$. Arrows show colocalization of VGAT puncta with neuronal soma. Data are represented as mean $\pm S E$. ${ }^{*} p<0.05$, two-tailed Student's $t$ test. 
A

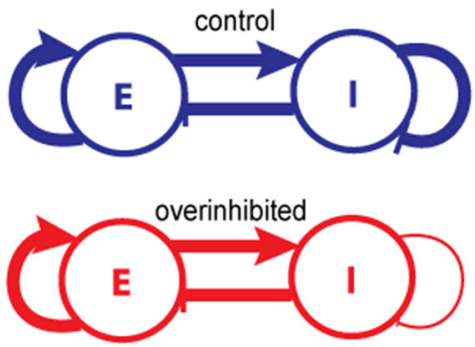

B

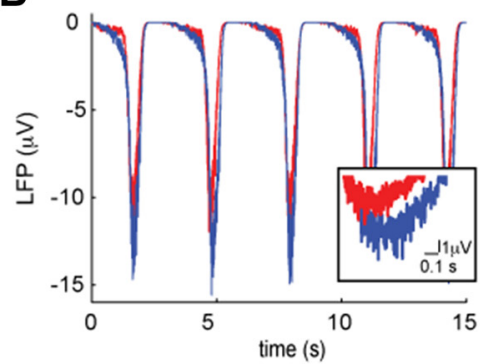

C

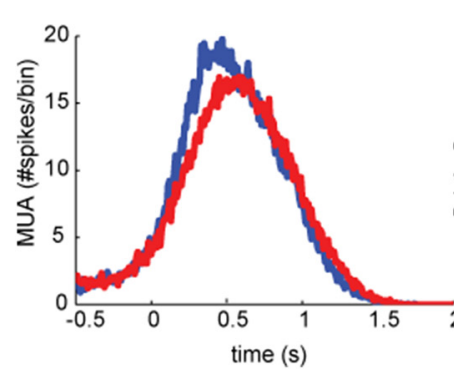

D

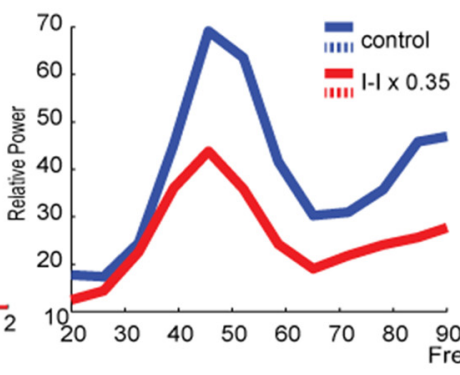

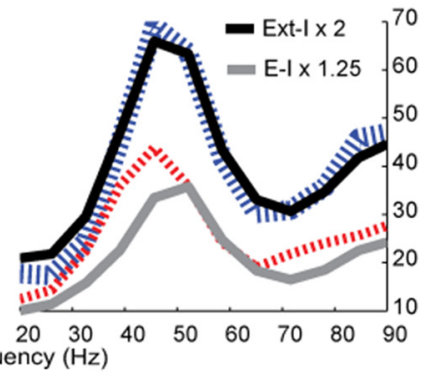

Figure 6. Neural network model. $\boldsymbol{A}$, Population-based diagram of the neural network model. The overinhibited network (red) corresponds to a $35 \%$ reduction change of the inhibitory-inhibitory coupling with respect to the control network (blue) described by Compte et al. (2003). E, Excitatory; I, inhibitory. $\boldsymbol{B}$, Simulated LFP traces considering 50 excitatory neurons showing the slow oscillatory dynamics. An UP state is enlarged for better resolution of the faster gamma fluctuations. C, Simulated MUA traces averaged around the UP states within 200 ms. Here MUA is defined as the number of spikes triggered in one time bin of $10 \mathrm{~ms}$. D, Relative power of the LFP computed during the UP states with respect to the power in the DOWN states for the control (blue) and overinhibited (red) networks. The gray and black curves show, respectively, the relative power of the LFP for a network with a 1.25 -fold increase in the excitatory to inhibitory connections and a network with a twofold increase in the amplitude of the external excitatory input onto the inhibitory population. The dashed and solid blue and red lines are the same lines. Note that the gray curve produces a shift of the gamma peak and a decrease of power at lower frequencies than the peak, hence showing a different effect than the red curve.

vertical axis of Figure $6 B$ is reduced compared to the experimental time traces in Figure 1, $B$ and $C$, corresponding to smaller amplitudes of the modeled LFP, which would account for a smaller number of neurons in the model. These results suggest that the reduction in the population firing rate and in the gamma power of the LFP in the TgDyrk1A mice could be explained by a decrease in the number of inhibitory-inhibitory contacts.

The firing activity in the network is triggered by an external excitatory train of spikes impinging on all neurons, aiming to account for long-range excitatory connections on the explicitly modeled local neuronal population. The gamma rhythm emerges due to the recurrence between excitatory and inhibitory neurons. In particular, the time course of inhibition determines the frequency within the gamma band (Compte et al., 2008). Firing in the inhibitory population triggers a period of time during which neurons are less likely to fire (Brunel and Wang, 2003; Bartos et al. 2007; Mazzoni et al. 2008). Hence, inhibition within the network can be boosted in two different ways: first, by increasing the presynaptic excitatory currents (either external or recurrent) on the inhibitory neurons, and second, by decreasing their presynaptic inhibitory currents (disinhibition). Figure $6 D$ shows that, in fact, disinhibition can target quite specifically the gamma peak, and frequencies above, by reducing its amplitude (red curve). Fostering either one of the two sources of excitation (to inhibitory neurons) produces the following responses. A slight increase in the recurrent excitation (gray curve) reduces power at all frequencies and produces a shift toward higher gamma rhythms. Further increasing this connectivity by the same relative change as we decrease inhibitory contacts on inhibitory neurons eliminates the slow oscillations, making it impossible to distinguish the UP and DOWN states (results not shown). Those behaviors contrast with our experimental observations in the TgDyrk1A mice, which, besides not showing an increase of the presynaptic excitatory punctae, do not display a shift toward higher gamma rhythms or disappearance of slow oscillations. On the other hand, increasing external excitation (black curve) does not affect the response of the network, probably allowing a resettlement of the excitatory-inhibitory balance. Thus, together, our modeling results indicate that the decrease in the relative UP/DOWN gamma power is likely associated with an effective increase in inhibition within the recurrent inhibitory connections.

\section{Discussion}

Our results demonstrate that Dyrk1A overexpression causes a decrease in network firing rate as well as a decay in gamma synchronization and subtle synaptic defects in parvalbumin positive neuronal populations. According to theoretical simulations in an in silico cerebral cortex model, reduced VGAT inhibitory contacts on parvalbumin cells of a magnitude equivalent to the one detected experimentally could by itself explain the decreased gamma synchrony along with a decrease in firing rate. Our results shed light on the impact of DYRK1A overexpression and suggest potential cortical network basis for the deficits of executive function in Down syndrome. Moreover, our experiments strongly point to the abnormal recurrent inhibition of fastspiking interneurons as a primary factor in the pathogenesis of the syndrome.

It has been suggested that the cognitive alteration in Down syndrome might be caused by impaired excitatory/inhibitory balance in hippocampal and cortical circuits. This hypothesis is largely based on some of the most consistent neuropathological findings in Down syndrome, a reduction of dendritic complexity and spine density in pyramidal cells, and increased inhibition. However, we still do not understand how this altered excitation/ 
inhibition balance could also impact the emergent activity in prefrontal circuits and what the specific contribution is of candidate genes to it.

We addressed here the question of whether the overexpression of Dyrk1A disrupts PFC emergent activity both in anesthetized and in awake animals. This activity is spontaneous and integrates membrane and synaptic properties as well as the excitatory/inhibitory balance of the local network and its afferent connections, providing quantitative information on its computational capabilities (Mattia and Sanchez-Vives, 2012). Previously described alterations in PFC slices of Dyrk1A transgenic mice, such as larger miniature EPSCs (Thomazeau et al., 2014) are relevant at the circuit level, but they do not predict how the PFC network will behave in vivo regarding its global excitability, firing rates, or power of beta and gamma oscillations.

A major finding obtained in our experiments regarding the emergent prefrontal activity of TgDyrk1A was the detection of a significant decrease of population firing rate during the periods of persistent activity of the slow oscillation or UP states. The recruitment of the local network that leads to UP states was delayed in TgDyrk1A mice compared to WTs, resulting in a slower slope in the DOWN to UP state transition. Additionally, the variability of the UP states' duration was increased. We also detected slowing of the wave propagation in the motor cortex. Slow waves preferentially originate in the frontal cortex and from there propagate backward both in humans (Massimini et al., 2004; Mohajerani et al., 2010) and mice (Ruiz-Mejias et al., 2011; Stroh et al., 2013). An enhanced inhibition (Sanchez-Vives et al., 2010) or decreased network excitability (Compte et al., 2003) can cause decreased wave propagation speeds. Because the deceleration is progressive, speeds would be slower at longer distances from the place where waves originate. This would explain why no speed differences were apparent in PFC, since it is too close to the origin of the wave, whereas differences were significant in the motor cortex.

The alteration of the slow waves (decreased firing rate, increased irregularity, slowed down propagation) under anesthesia is a good predictor that spontaneous slow waves will also be affected during slow wave sleep, given that they are highly similar and emerge from the same circuit (Steriade et al., 1993). There is accumulated evidence of the relationship between slow wave sleep and memory consolidation (Mölle and Born, 2011; Djonlagic et al., 2012), and thus alterations in slow wave generation may contribute to memory deficits. Indeed, polysomnographic studies (Clausen et al., 1977; Babiloni et al., 2009; Velikova et al., 2011) showed that fragmentation and disrupted sleep architecture commonly observed throughout the lifespan of individuals with Down syndrome are also detected in Down syndrome mouse models (Colas et al., 2004; Colas et al., 2008) and correlate with the cognitive outcome (Breslin et al. 2014).

We also found that the power of oscillations in the gamma range was decreased in TgDyrk1A with respect to WT mice. The failure to generate enough power in high gamma frequencies during UP states was identified in the emergent patterns of deeply anesthetized animals and was consistent with recordings in awake chronically implanted animals. Fast cortical oscillations in the beta-gamma range are involved in several cognitive processes involving the PFC, such as attention, decision making, learning, and working memory (Whittington et al., 2011; Buzsáki and Wang, 2012; Siegel et al., 2012). Gamma oscillations are upregulated by neuromodulators during cognitive performance; however, the local mechanisms for their generation already exist in the isolated network (Destexhe et al., 2007; Compte et al., 2008;
Whittington et al., 2011). Our study represents the first evidence of decreased gamma synchronization accompanied by electrophysiological signs of a decreased excitability in the cortex of a mouse model overexpressing a Down syndrome candidate gene. Alterations in oscillatory patterns have also been detected in electroencephalography (EEG) recordings in Down syndrome humans (Clausen et al., 1977; Babiloni et al., 2009; Velikova et al., 2011). Several authors (Murata et al., 1994; Velikova et al., 2011) have detected shifts toward lower frequencies in mean EEG signals up to the beta band, as well as decreased low beta $(13-18 \mathrm{~Hz})$ oscillatory activity in adults and aged Down syndrome individuals. Babiloni et al. (2009) found decreased beta and gamma waves in Down syndrome adolescents that were correlated with cognitive psychometric measurements (Babiloni et al., 2009). Nevertheless, given the limitations of EEG recordings, none of them referred to frequency bands beyond $45 \mathrm{~Hz}$.

As mentioned above, the observed physiological changes are compatible with an overinhibited prefrontal network (SanchezVives et al., 2010). In our study, TgDyrk1A mice did not show differences in the number of inhibitory interneurons in the prefrontal cortex. However, the proportion of excitatory versus inhibitory presynaptic punctae (VGLUT1/VGAT ratio) was significantly increased due to a reduced number of presynaptic inhibitory vesicles that selectively contact with parvalbumin interneurons. The net effect would be a reduced inhibitory input on parvalbumin interneurons, which is compatible with a more inhibited network, so that disinhibited parvalbumin neurons would more efficiently inhibit pyramidal neurons, in agreement with our functional findings. In turn, the reduced inhibitory connectivity over parvalbumin cells would produce a lack of capability of interneurons to synchronize in high-frequency network activity, a relevant role of inhibitory-inhibitory synapses (Börgers and Kopell, 2003; Compte et al., 2008; Whittington et al., 2011); in addition, perisomatic inhibition is essential for gamma oscillations (for review, see Whittington et al., 2011; Buzsáki and Wang, 2012). Thus, we propose that disinhibition of parvalbumin neurons would result in a reduced oscillatory activity in the gamma range (Bartos et al., 2007; Whittington et al., 2011), a hypothesis that we have tested here in a validated computational model of the cerebral cortex (Compte et al., 2003; Compte et al., 2008). The resulting aberrant spontaneous gamma oscillations suggest that the normal upregulation of gamma waves may be impaired when constructing cognitive assemblies through rhythmic activity in prefrontal-dependent tasks (Fitzgibbon et al., 2004; Siegel et al., 2012). Although here we did not use a Dyrk1A kinase inhibitor to establish a direct link with excess kinase activity and the observed phenotypes, previous work (De la Torre et al., 2014, Thomazeau et al., 2014) has demonstrated that the corticohippocampal and, specifically, prefrontal cortex phenotypes of different transgenic strains overexpressing Dyrk1A are rescued using a DYRK1A kinase inhibitor (epigallocatechin-3gallate). These suggest that overexpression of Dyrk1A alters the balance of excitation and inhibition toward a more inhibited network, leading to aberrant network activity and support the view that dysfunction of cortical fast-spiking interneurons might be central to the pathophysiology of Down syndrome.

\section{References}

Altafaj X, Dierssen M, Baamonde C, Martí E, Visa J, Guimerà J, Oset M, González JR, Flórez J, Fillat C, Estivill X (2001) Neurodevelopmental delay, motor abnormalities and cognitive deficits in transgenic mice overexpressing Dyrk1A (minibrain), a murine model of Down's syndrome. Hum Mol Genet 10:1915-1923. CrossRef Medline

Babiloni C, Albertini G, Onorati P, Vecchio F, Buffo P, Sarà M, Condoluci C, 
Pistoia F, Carducci F, Rossini PM (2009) Inter-hemispheric functional coupling of eyes-closed resting EEG rhythms in adolescents with Down syndrome. Clin Neurophysiol 120:1619-1627. CrossRef Medline

Ball SL, Holland AJ, Watson PC, Huppert FA (2010) Theoretical exploration of the neural bases of behavioural disinhibition, apathy and executive dysfunction in preclinical Alzheimer's disease in people with Down's syndrome: potential involvement of multiple frontal-subcortical neuronal circuits. J Intellect Disabil Res 54:320-336. CrossRef Medline

Bartos M, Vida I, Jonas P (2007) Synaptic mechanisms of synchronized gamma oscillations in inhibitory interneuron networks. Nat Rev Neurosci 8:45-56. CrossRef Medline

Bédard C, Destexhe A (2009) Macroscopic models of local field potentials and the apparent 1/f noise in brain activity. Biophys J 96:2589-2603. CrossRef Medline

Beim Graben P, Rodrigues S (2012) A biophysical observation model for field potentials of networks of leaky integrate-and-fire neurons. Front Comput Neurosci 6:100. Medline

Benavides-Piccione R, Dierssen M, Ballesteros-Yáñez I, Martínez de Lagrán M, Arbonés ML, Fotaki V, DeFelipe J, Elston GN (2005) Alterations in the phenotype of neocortical pyramidal cells in the Dyrk1A+/- mouse. Neurobiol Dis 20:115-122. CrossRef Medline

Blundell J, Tabuchi K, Bolliger MF, Blaiss CA, Brose N, Liu X, Südhof TC, Powell CM (2009) Increased anxiety-like behavior in mice lacking the inhibitory synapse cell adhesion molecule neuroligin 2. Genes Brain Behav 8:114-126. CrossRef Medline

Börgers C, Kopell N (2003) Synchronization in networks of excitatory and inhibitory neurons with sparse, random connectivity. Neural Comput 15:509-538. CrossRef Medline

Breslin J, Spanò G, Bootzin R, Anand P, Nadel L, Edgin J (2014) Obstructive sleep apnea syndrome and cognition in Down syndrome. Dev Med Child Neurol 56:657-664. CrossRef Medline

Brunel N, Wang XJ (2003) What determines the frequency of fast network oscillations with irregular neural discharges? I. Synaptic dynamics and excitation-inhibition balance. J Neurophysiol 90:415-430. CrossRef Medline

Buzsáki G, Wang XJ (2012) Mechanisms of gamma oscillations. Annu Rev Neurosci 35:203-225. CrossRef Medline

Clausen J, Sersen EA, Lidsky A (1977) Sleep patterns in mental retardation: Down's syndrome. Electroencephalogr Clin Neurophysiol 43:183-191. CrossRef Medline

Colas D, London J, Gharib A, Cespuglio R, Sarda N (2004) Sleep-wake architecture in mouse models for Down syndrome. Neurobiol Dis 16: 291-299. CrossRef Medline

Colas D, Valletta JS, Takimoto-Kimura R, Nishino S, Fujiki N, Mobley WC, Mignot E (2008) Sleep and EEG features in genetic models of Down syndrome. Neurobiol Dis 30:1-7. CrossRef Medline

Compte A, Sanchez-Vives MV, McCormick DA, Wang XJ (2003) Cellular and network mechanisms of slow oscillatory activity $(<1 \mathrm{~Hz})$ and wave propagations in a cortical network model. J Neurophysiol 89:2707-2725. CrossRef Medline

Compte A, Reig R, Descalzo VF, Harvey MA, Puccini GD, Sanchez-Vives MV (2008) Spontaneous high-frequency $(10-80 \mathrm{~Hz})$ oscillations during up states in the cerebral cortex in vitro. J Neurosci 28:13828-13844. CrossRef Medline

Courcet JB, Faivre L, Malzac P, Masurel-Paulet A, Lopez E, Callier P, Lambert L, Lemesle M, Thevenon J, Gigot N, Duplomb L, Ragon C, Marle N, Mosca-Boidron AL, Huet F, Philippe C, Moncla A, Thauvin-Robinet C (2012) The DYRK1A gene is a cause of syndromic intellectual disability with severe microcephaly and epilepsy. J Med Genet 49:731-736. CrossRef Medline

De la Torre R, De Sola S, Pons M, Duchon A, de Lagran MM, Farré M, Fitó M, Benejam B, Langohr K, Rodriguez J, Pujadas M, Bizot JC, Cuenca A, Janel N, Catuara S, Covas MI, Blehaut H, Herault Y, Delabar JM, Dierssen M (2014) Epigallocatechin-3-gallate, a DYRK1A inhibitor, rescues cognitive deficits in Down syndrome mouse models and in humans. Mol Nutr Food Res 58:278-288. CrossRef Medline

de Sola S, de la Torre R, Sánchez-Benavides G, Benejam B, Cuenca-Royo A, Del Hoyo L, Rodríguez J, Catuara-Solarz S, Sanchez-Gutierrez J, DueñasEspin I, Hernandez G, Peña-CasanovaJ, Langohr K, Videla S, Blehaut H, Farre M, Dierssen M, Group TS (2015) A new cognitive evaluation battery for Down syndrome and its relevance for clinical trials. Front Psychol 6:708. Medline
Destexhe A, Hughes SW, Rudolph M, Crunelli V (2007) Are corticothalamic 'up' states fragments of wakefulness? Trends Neurosci 30:334-342. CrossRef Medline

Dierssen M (2012) Down syndrome: the brain in trisomic mode. Nat Rev Neurosci 13:844-858. CrossRef Medline

Djonlagic I, Saboisky J, Carusona A, Stickgold R, Malhotra A (2012) Increased sleep fragmentation leads to impaired off-line consolidation of motor memories in humans. PLoS One 7:e34106. CrossRef Medline

Eichler SA, Meier JC (2008) E-I balance and human diseases - from molecules to networking. Front Mol Neurosci 1:2. Medline

Fitzgibbon SP, Pope KJ, Mackenzie L, Clark CR, Willoughby JO (2004) Cognitive tasks augment gamma EEG power. Clin Neurophysiol 115: 1802-1809. CrossRef Medline

Fotaki V, Dierssen M, Alcántara S, Martínez S, Martí E, Casas C, Visa J, Soriano E, Estivill X, Arbonés ML (2002) Dyrk1A haploinsufficiency affects viability and causes developmental delay and abnormal brain morphology in mice. Mol Cell Biol 22:6636-6647. CrossRef Medline

Franklin KBJ, Paxinos G (2008) The mouse brain in stereotaxic coordinates, Ed 2. New York: Academic.

Gillespie DT (1996) Exact numerical simulation of the Ornstein-Uhlenbeck process and its integral. Physical review. E, Statistical physics, plasmas, fluids, and related interdisciplinary topics 54:2084-2091. CrossRef

Gruart A, Muñoz MD, Delgado-GarcíaJM (2006) Involvement of the CA3CA1 synapse in the acquisition of associative learning in behaving mice. J Neurosci 26:1077-1087. CrossRef Medline

Hasenstaub A, Shu Y, Haider B, Kraushaar U, Duque A, McCormick DA (2005) Inhibitory postsynaptic potentials carry synchronized frequency information in active cortical networks. Neuron 47:423-435. CrossRef Medline

Jahr CE, Stevens CF (1990) Voltage dependence of NMDA-activated macroscopic conductances predicted by single-channel kinetics. J Neurosci 10:3178-3182. Medline

Jernigan TL, Bellugi U, Sowell E, Doherty S, Hesselink JR (1993) Cerebral morphologic distinctions between Williams and Down syndromes. Arch Neurol 50:186-191. CrossRef Medline

Ji J, Lee H, Argiropoulos B, Dorrani N, Mann J, Martinez-Agosto JA, GomezOspina N, Gallant N, Bernstein JA, Hudgins L, Slattery L, Isidor B, Le Caignec C, David A, Obersztyn E, Wiśniowiecka-Kowalnik B, Fox M, Deignan JL, Vilain E, Hendricks E, et al. (2015) DYRK1A haploinsufficiency causes a new recognizable syndrome with microcephaly, intellectual disability, speech impairment, and distinct facies. Eur J Hum Genet 23:1473-1481. CrossRef Medline

Makarov VA, Makarova J, Herreras O (2010) Disentanglement of local field potential sources by independent component analysis. J Comput Neurosci 29:445-457. CrossRef Medline

Martí E, Altafaj X, Dierssen M, de la Luna S, Fotaki V, Alvarez M, Pérez-Riba M, Ferrer I, Estivill X (2003) Dyrk1A expression pattern supports specific roles of this kinase in the adult central nervous system. Brain Res 964:250-263. CrossRef Medline

Martinez de Lagran M, Altafaj X, Gallego X, Martí E, Estivill X, Sahún I, Fillat C, Dierssen M (2004) Motor phenotypic alterations in TgDyrk1a transgenic mice implicate DYRK1A in Down syndrome motor dysfunction. Neurobiol Dis 15:132-142. CrossRef Medline

Martinez de Lagran M, Benavides-Piccione R, Ballesteros-Yañez I, Calvo M, Morales M, Fillat C, Defelipe J, Ramakers GJ, Dierssen M (2012) Dyrk1A influences neuronal morphogenesis through regulation of cytoskeletal dynamics in mammalian cortical neurons. Cereb cortex 22: 2867-2877. CrossRef Medline

Massimini M, Huber R, Ferrarelli F, Hill S, Tononi G (2004) The sleep slow oscillation as a traveling wave. J Neurosci 24:6862-6870. CrossRef Medline

Mattia M, Sanchez-Vives MV (2012) Exploring the spectrum of dynamical regimes and timescales in spontaneous cortical activity. Cogn Neurodyn 6:239-250. CrossRef Medline

Mazzoni A, Panzeri S, Logothetis NK, Brunel N (2008) Encoding of naturalistic stimuli by local field potential spectra in networks of excitatory and inhibitory neurons. PLoS Comput Biol 4:e1000239. CrossRef Medline

Mohajerani MH, McVea DA, Fingas M, Murphy TH (2010) Mirrored bilateral slow-wave cortical activity within local circuits revealed by fast bihemispheric voltage-sensitive dye imaging in anesthetized and awake mice. J Neurosci 30:3745-3751. CrossRef Medline 
Mölle M, Born J (2011) Slow oscillations orchestrating fast oscillations and memory consolidation. Prog Brain Res 193:93-110. CrossRef Medline

Møller RS, Kübart S, Hoeltzenbein M, Heye B, Vogel I, Hansen CP, Menzel C, Ullmann R, Tommerup N, Ropers HH, Tümer Z, Kalscheuer VM (2008) Truncation of the Down syndrome candidate gene DYRK1A in two unrelated patients with microcephaly. Am J Hum Genet 82:1165-1170. CrossRef Medline

Murata T, Koshino Y, Omori M, Murata I, Nishio M, Horie T, Isaki K (1994) Quantitative EEG study on premature aging in adult Down's syndrome. Biol Psychiatry 35:422-425. CrossRef Medline

Nir Y, Staba RJ, Andrillon T, Vyazovskiy VV, Cirelli C, Fried I, Tononi G (2011) Regional slow waves and spindles in human sleep. Neuron 70: 153-169. CrossRef Medline

Park J, Song WJ, Chung KC (2009) Function and regulation of Dyrk1A: towards understanding Down syndrome. Cell Mol Life Sci 66:3235-3240. CrossRef Medline

Pujol J, del Hoyo L, Blanco-Hinojo L, de Sola S, Macià D, Martínez-Vilavella G, Amor M, Deus J, Rodríguez J, Farré M, Dierssen M, de la Torre R (2015) Anomalous brain functional connectivity contributing to poor adaptive behavior in Down syndrome. Cortex 64:148-156. CrossRef Medline

Raz N, Torres IJ, Briggs SD, Spencer WD, Thornton AE, Loken WJ, Gunning FM, McQuain JD, Driesen NR, Acker JD (1995) Selective neuroanatomic abnormalities in Down's syndrome and their cognitive correlates: evidence from MRI morphometry. Neurology 45:356-366. CrossRef Medline

Reig R, Mattia M, Compte A, Belmonte C, Sanchez-Vives MV (2010) Temperature modulation of slow and fast cortical rhythms. J Neurophysiol 103:1253-1261. CrossRef Medline

Rowe J, Lavender A, Turk V (2006) Cognitive executive function in Down's syndrome. Br J Clin Psychol 45:5-17. CrossRef Medline

Ruiz-Mejias M, Ciria-Suarez L, Mattia M, Sanchez-Vives MV (2011) Slow and fast rhythms generated in the cerebral cortex of the anesthetized mouse. J Neurophysiol 106:2910-2921. CrossRef Medline

Sanchez-Vives MV, Mattia M, Compte A, Perez-Zabalza M, Winograd M, Descalzo VF, Reig R (2010) Inhibitory modulation of cortical up states. J Neurophysiol 104:1314-1324. CrossRef Medline
Siegel M, Donner TH, Engel AK (2012) Spectral fingerprints of large-scale neuronal interactions. Nat Rev Neurosci 13:121-134. Medline

Souchet B, Guedj F, Sahún I, Duchon A, Daubigney F, Badel A, Yanagawa Y, Barallobre MJ, Dierssen M, Yu E, Herault Y, Arbones M, Janel N, Créau N, Delabar JM (2014) Excitation/inhibition balance and learning are modified by Dyrkla gene dosage. Neurobiol Dis 69:65-75. CrossRef Medline

Steriade M, Amzica F (1996) Intracortical and corticothalamic coherency of fast spontaneous oscillations. Proc Natl Acad Sci U S A 93:2533-2538. CrossRef Medline

Steriade M, Nuñez A, Amzica F (1993) A novel slow ( $<1 \mathrm{~Hz}$ ) oscillation of neocortical neurons in vivo: depolarizing and hyperpolarizing components. J Neurosci 13:3252-3265. Medline

Stroh A, Adelsberger H, Groh A, Rühlmann C, Fischer S, Schierloh A, Deisseroth K, Konnerth A (2013) Making waves: initiation and propagation of corticothalamic Ca2+ waves in vivo. Neuron 77:1136-1150. CrossRef Medline

Tejedor FJ, Hämmerle B (2011) MNB/DYRK1A as a multiple regulator of neuronal development. FEBS J 278:223-235. CrossRef Medline

Thomazeau A, Lassalle O, Iafrati J, Souchet B, Guedj F, Janel N, Chavis P, Delabar J, Manzoni OJ (2014) Prefrontal deficits in a murine model overexpressing the down syndrome candidate gene dyrk1a. J Neurosci 34:1138-1147. CrossRef Medline

van Bon BW, Hoischen A, Hehir-Kwa J, de Brouwer AP, Ruivenkamp C, Gijsbers AC, Marcelis CL, de Leeuw N, Veltman JA, Brunner HG, de Vries BB (2011) Intragenic deletion in DYRK1A leads to mental retardation and primary microcephaly. Clin Genet 79:296-299. CrossRef Medline

Velikova S, Magnani G, Arcari C, Falautano M, Franceschi M, Comi G, Leocani L (2011) Cognitive impairment and EEG background activity in adults with Down's syndrome: a topographic study. Hum Brain Mapp 32:716-729. CrossRef Medline

Whittington MA, Cunningham MO, LeBeau FE, Racca C, Traub RD (2011) Multiple origins of the cortical gamma rhythm. Dev Neurobiol 71: 92-106. CrossRef Medline

Wisniewski KE (1990) Down syndrome children often have brain with maturation delay, retardation of growth, and cortical dysgenesis. Am J Med Genet Suppl 7:274-281. Medline 